\title{
ANALISIS KESEDIAAN MEMBAYAR (WILLINGNESS TO PAY) KONSUMEN TERHADAP SAYURAN ORGANIK DI PASAR MODERN PURWOKERTO DAN FAKTOR YANG MEMENGARUHI
}

\author{
Fatha Fajria*, Dyah Ethika, Djeimy Kusnaman \\ Jurusan Agribisnis, Fakultas Pertanian, Universitas Jenderal Soedirman \\ Jl. Dr. Soeparno 61, Karawangkal, Purwokerto 53123 \\ *Corresponding author: fathafajria30@gmail.com
}

\begin{abstract}
Organic vegetable tend to have higher price than inorganic vegetable, so that the majority of consumers consider vegetable organic products as an expensive food product. This study aims to describe the characteristics of organic vegetable consumer, to analyze the maximum average of willingness to pay and the factors affected the willingness to pay of organic vegetables. This research applied survey method and conducted in the modern market of Purwokerto in August until September 2019. One hundred respondents were taken by using purposive sampling method. Analysis of the data used is descriptive, Contingent Valuation Method (CVM) and Logistic Regression Analysis. The results showed that the average maximum of WTP for organic vegetable lettuce is higher $9.15 \%$, mustard greens is higher $8.70 \%$, kale is higher $8.35 \%$, spinach is higher $10.50 \%$, and broccoli is higher $10.05 \%$ than recent price of it. The factors that significally affected the willingness to pay is education, employment, and income, while age, sex, status of marriage, price, and quality do not have any effects to WTP.
\end{abstract}

Keywords: WTP, organic vegetables, CVM, logistic regression

\begin{abstract}
Abstrak: Sayur organik cenderung memiliki harga yang lebih tinggi dibandingkan dengan sayur anorganik, sehingga sebagian konsumen menganggap produk sayur organik sebagai produk pangan yang mahal. Penelitian ini bertujuan untuk mendeskripsikan karakteristik konsumen sayuran organik, menganalisis besarnya nilai rata-rata kesediaan membayar atau Willingness to Pay maksimum serta faktor yang memengaruhi kesediaan membayar sayuran organik. Metode penelitian yang digunakan adalah metode survei dan dilaksanakan di pasar modern Purwokerto pada bulan Agustus sampai September 2019. Pengambilan sampel secara Purposive Sampling yaitu sebanyak 100 orang. Analisis data yang digunakan adalah deskriptif, Contingent Valuation Method (CVM) dan Analisis Regresi Logistik. Hasil penelitian menunjukkan bahwa nilai rata-rata maksimum WTP sayur organik untuk jenis sayur selada lebih tinggi $9,15 \%$, sawi lebih tinggi $8,70 \%$, kangkung lebih tinggi $8,35 \%$, bayam lebih tinggi $10,50 \%$, dan brokoli lebih tinggi $10,05 \%$ dari harga pada saat penelitian. Faktor yang memengaruhi kesediaan membayar secara signifikan adalah pendidikan, pekerjaan, dan pendapatan sedangkan usia, jenis kelamin, status pernikahan, harga, dan kualitas tidak memiliki pengaruh signifikan.
\end{abstract}

Kata kunci: WTP, sayuran organik, CVM, regresi logistik

\section{PENDAHULUAN}

Pola hidup sehat yang ramah lingkungan telah menjadi tren baru, masyarakat mulai meninggalkan pola hidup lama yang menggunakan bahan kimia non-alami, seperti pupuk, pestisida kimia sintetis, dan hormon tumbuh dalam budidaya pertanian. Pola hidup 
Fajria, F., Ethika, D., Kusnaman, D. : Analisis Kesediaan Membayar ...

sehat ini mengharuskan jaminan bahwa produk pertanian harus beratribut aman dikonsumsi, kandungan nutrisi tinggi dan ramah lingkungan. Pangan yang sehat dan bergizi tinggi ini dapat diproduksi dengan metode pertanian organik salah satunya yaitu sayuran organik (Mayrowani, 2012; Yakin, 1997).

Sayur organik banyak dijumpai di pasar modern karena sasaran pasar sayur organik merupakan konsumen kalangan menengah atas. Faktor harga menjadi salah satu penyebab belum meratanya penyebaran produk karena produk sayur organik memiliki harga yang lebih tinggi dibandingkan dengan sayur anorganik. Persepsi mengenai harga sayur organik yang dianggap mahal merupakan kendala bagi produsen, oleh karena itu dalam penentuan harga jual penting untuk diketahui seberapa besar kesediaan konsumen membayar atau willingness to pay (WTP) untuk mendapatkan produk sayur organik.

Pertumbuhan perekonomian di Purwokerto semakin meningkat. Tingginya harga di kota tersebut diimbangi dengan majunya perkembangan infrastruktur, salah satunya adalah maraknya pembangunan pusat perbelanjaan baik modern maupun tradisional. Upah Minimum Regional (UMR) Kabupaten Banyumas tahun 2019 mengalami kenaikan yaitu sebesar Rp1.750.000 atau naik sebesar Rp161.000 dari UMR tahun sebelumnya sebesar Rp1.589.000. Menurut Priambodo dan Najib (2014), peningkatan pendapatan akan mengubah perilaku konsumsi masyarakat. Selain itu, masyarakat juga akan lebih menyadari pentingnya hidup sehat dengan mengkonsumsi sayuran organik, meski harga jual sayuran organik di pasar meningkat karena kenaikan biaya produksi sebagai akibat dari peningkatan kualitas produk. Kusumaningsih et al. (2019) menyatakan bahwa lingkungan serta meningkatnya pengetahuan dan keasadaran akan manfaat sehat dari pangan organik akan meningkatkan konsumsi pangan organik. Demikian pula dengan tingkat konsumsi masyarakat Purwokerto yang semakin tinggi khususnya produk pangan. Oleh karena itu, perlu diketahui seberapa besar kesediaan konsumen membayar atau Willingness To Pay (WTP) untuk mendapatkan produk sayur organik. Nilai WTP menggambarkan keinginan membayar seseorang terhadap sayuran organik yang dihasilkan oleh sumber daya alam dan lingkungan. Tujuan dari penelitian ini untuk 1) mendeskripsikan karakteristik konsumen sayuran organik, 2) menganalisis besarnya nilai rata-rata kesediaan membayar atau Willingness to Pay maksimum, dan 3) menganalisis faktor yang memengaruhi kesediaan membayar sayuran organik.

\section{METODE PENELITIAN}

Penelitian ini dilaksanakan di lima pasar modern Purwokerto yaitu Rita Swalayan, Rita Pasaraya Isola, Aroma, Moro dan Cherry Fresh Fruit Market. Penentuan tempat dipilih secara sengaja (purposive). Metode penelitian yang digunakan adalah metode survei. Penelitian ini dilaksanakan pada bulan Agustus 2019 sampai September 2019. Penentuan responden konsumen sayur organik dilakukan menggunakan metode purposive sampling dimana sampel dipilih berdasarkan karakteristik yang disesuaikan. Populasi konsumen sayur organik tidak diketahui secara pasti jumlahnya sehingga digunakan rumus Lemeshow dan Levy (1997) untuk mendapatkan jumlah sampel, dengan rumus sebagai berikut:

$$
\begin{aligned}
& \mathrm{n}=\frac{\mathrm{z}^{2} \times \mathrm{P}(1-\mathrm{P})}{\mathrm{d}^{2}} \\
& \mathrm{n}=\frac{(1,96)^{2} \times 0,5}{(0,1)^{2}} \\
& \mathrm{n}=\frac{3,8416 \times 0,25}{(0,01)} \\
& \mathrm{n}=96,04
\end{aligned}
$$

\section{Keterangan:}

$\mathrm{n}=$ jumlah sampel

$\mathrm{z}=$ skor $\mathrm{z}$ pada kepercayaan $95 \%=1,96$

$\mathrm{p}=$ maksimal estimasi $=0,5$

$\mathrm{d}=$ alpha atau sampling error $=10 \%=0,1$

Berdasarkan perhitungan dengan rumus, didapatkan hasil yaitu 96 responden dan dibulatkan menjadi 100 responden. Jumlah sampel tersebut dialokasikan ke lima lokasi pasar modern yang dijadikan lokasi penelitian.

Analisis data yang digunakan dalam penelitian ini adalah analisis deskriptif, CVM, dan regresi logistik. Analisis deskriptif dalam penelitian ini dilakukan untuk menjelaskan karakteristik konsumen produk sayur organik di 
$\frac{p}{1-p}=\beta_{0}+\beta_{1} \mathrm{X}_{1}+\beta_{2} \mathrm{X}_{2}+\beta_{3} \mathrm{X}_{3}+\beta_{4} \mathrm{X}_{4}+\beta_{5} \mathrm{X}_{5}+\beta_{6} \mathrm{X}_{6}+\beta_{7} \mathrm{X}_{7}+\beta_{8} \mathrm{X}_{8}$

$\mathrm{Y}=\frac{\mathrm{e} \beta 0+\beta 1 X 1+\beta 2 X 2+\beta 3 X 3+\beta 4 X 4+\beta 5 X 5+\beta 6 X 6+\beta 7 X 7+\beta 8 X 8}{1+\mathrm{e} \beta 0+\beta 1 X 1+\beta 2 X 2+\beta 3 X 3+\beta 4 X 4+\beta 5 X 5+\beta 6 X 6+\beta 7 X 7+\beta 8 X 8}$

Keterangan:

$\mathrm{Y}=$ variabel dummy untuk kesediaan membayar sayuran organik

$\mathrm{Y}=0=$ tidak bersedia membayar

$\mathrm{Y}=1$ = bersedia membayar

$\mathrm{X} 1=\mathrm{usia}$

$\mathrm{X} 2=$ jenis kelamin

X3 = tingkat pendidikan

$\mathrm{X} 4=$ status pernikahan

$\mathrm{X} 5=$ pekerjaan

$\mathrm{X} 6=$ pendapatan

$\mathrm{X} 7=$ kualitas

$\mathrm{X} 8=$ harga

$\mathrm{e}=$ Tetapan $\mathrm{e}$

pasar modern wilayah Purwokerto. Nilai WTP dari konsumen dapat diperoleh dengan metode Contingent Valuation Method (CVM). Analisis regresi logistik digunakan untuk menguji hubungan variabel independen dan variabel dependen, dimana variabel dependen yang digunakan bersifat dikotomik. Bentuk model persamaan regresi logistik menurut (Suharjo, 2008) seperti dalam persamaan 2.

Berdasarkan persamaan 2, maka model analisis regresi logistik pada penelitian ini dinyatakan seperti dalam persamaan 3 .

Uji yang digunakan dalam model regresi logistik adalah uji $\mathrm{G}$ atau secara serempak dan uji Wald atau secara parsial.

Hipotesis yang digunakan untuk uji $\mathrm{G}$ adalah:

$\mathrm{HO}$ : variabel independen secara serempak tidak memiliki pengaruh secara nyata terhadap variabel dependen.

H1 : variabel independen secara serempak memiliki pengaruh secara nyata terhadap variabel dependen.

Hipotesis ditolak jika $p$-value $<\alpha$, yang mengartikan bahwa variabel independen secara serentak mempengaruhi variabel dependen.

Hipotesis yang digunakan untuk uji Wald adalah:

HO : variabel independen ke-i tidak mempunyai pengaruh secara nyata terhadap variabel dependen.

$\mathrm{Hl}$ : variabel independen ke-i mempunyai pengaruh secara nyata terhadap variabel dependen.
Hipotesis ditolak jika $p$-value $<\alpha$, yang mengartikan bahwa variabel independen ke-i secara parsial mempengaruhi variabel dependen. $\alpha=$ tingkat signifikansi 0,05 .

Odds ratio

Interpretasi dari odds ratio merupakan ukuran risiko, atau kecenderungan untuk mengalami kejadian tertentu antara satu kategori dengan kategori lainnya, pada penelitian ini yaitu bersedia atau tidak bersedia untuk membayar lebih untuk memperoleh produk sayur organik. Nilai koefisien odds ratio dinyatakan dalam $\exp (\beta)$, yang menyatakan risiko, atau kecenderungan pengaruh observasi dengan kategori suatu $\mathrm{X}$ adalah berapa kali lipat jika dibandingkan dengan observasi dengan kategori lainnya (Maddala, 2006; Wooldridge, 2013).

\section{HASIL DAN PEMBAHASAN}

\section{Karakteristik Konsumen}

Berdasarkan hasil penelitian didapatkan hasil yang berbeda-beda pada setiap karakteristik responden yang diukur. Perbedaan karakteristik yang berasal dari faktor budaya, kelas sosial, pengaruh pribadi dan keluarga, serta situasi dapat mempengaruhi perilaku konsumen dalam melakukan pembelian dan kesediaannya membayar lebih tinggi. Responden didominasi oleh perempuan, rata-rata usia 27 tahun, pendidikan terakhir Strata 1, sudah menikah, rata-rata bekerja, rata-rata pendapatan sebesar 
Rp4.500.000 per bulan, membeli produk sayur organik dengan rentang harga kurang dari Rp10.000, memberi skor 8 atau baik pada kualitas produk sayur organik.

\section{Kesediaan Membayar}

Sebanyak 81 dari 100 orang menyatakan bersedia membayar lebih tinggi dari harga saat penelitian untuk memperoleh produk sayur organik, sementara 19 orang sisanya menyatakan tidak bersedia. Alasan utama tidak bersedianya responden membayar lebih karena harga sayur organik mahal, sebagian tidak bisa membedakan sayur organik atau anorganik, sayur organik tidak selalu tersedia pada lokasi pembelian dan jenis sayur organik terbatas. Dari tawaran kenaikan antara 5\% sampai dengan $20 \%$ yang diajukan, responden memiliki kesediaan yang berbeda-beda yang disajikan pada Tabel 1.

Tabel 1. Sebaran persentase responden yang bersedia membayar lebih

\begin{tabular}{cc}
\hline $\begin{array}{c}\text { Kesediaan Membayar } \\
\text { Lebih (\%) }\end{array}$ & $\begin{array}{c}\text { Jumlah Responden } \\
\text { (orang) }\end{array}$ \\
\hline 5 & 30 \\
10 & 37 \\
15 & 9 \\
20 & 5 \\
\hline Total & 81
\end{tabular}

Sumber: Data Primer, 2019.

Tabel 1 menunjukkan kenaikan harga yang bersedia dibayarkan konsumen sebesar $10 \%$ lebih tinggi dari harga saat penelitian. Keadaan ini menunjukkan konsumen di tempat penelitian memiliki kemampuan bersedia membayar lebih untuk produk sayur organik. Hal ini dapat dipengaruhi konsumen dengan latar belakang pendidikan menengah sampai tinggi cenderung memiliki pengetahuan mengenai pentingnya kesehatan makanan yang dikonsumsinya. Faktor pekerjaan juga memiliki peluang untuk bersedia membayar lebih karena pekerjaan menentukan pola konsumsi individu dan keluarga terkait dengan pendapatan yang dialokasikan, serta pendapatan juga mempengaruhi kesediaan membayar lebih karena rata-rata pendapatan konsumen tergolong memiliki pendapatan cukup tinggi sehingga dapat mengalokasikan sebagian kecil untuk membeli sayur organik yang lebih mahal.

\section{Perhitungan rata-rata WTP}

Perhitungan rata-rata maksimum WTP diperoleh dari perkalian antara harga awal produk atau nilai WTP dengan frekuensi relatif tiap komoditas sayur organik dan nilai WTP yang digunakan adalah nilai tengah. Hasil perhitungan rata-rata maksimum WTP dapat dilihat pada Tabel 2.

Tabel 2. Rata-rata maksimum WTP

\begin{tabular}{cccc}
\hline $\begin{array}{c}\text { Jenis } \\
\text { Sayur } \\
\text { Organik }\end{array}$ & $\begin{array}{c}\text { Harga } \\
\text { Awal } \\
\text { Produk } \\
(\mathrm{Rp})\end{array}$ & $\begin{array}{c}\text { Rata-Rata } \\
\text { Maksimum } \\
\text { WTP (Rp) }\end{array}$ & $\begin{array}{c}\text { Persentase } \\
\text { Peningkatan } \\
(\%)\end{array}$ \\
\hline Selada & 7350 & 8022,525 & $9,15 \%$ \\
Sawi & 4950 & 5380,65 & $8,70 \%$ \\
Kangkung & 4150 & 4496,525 & $8,35 \%$ \\
Bayam & 5500 & 6077,5 & $10,50 \%$ \\
Brokoli & 8962 & 9862,681 & $10,05 \%$ \\
\hline
\end{tabular}

Sumber: Data Primer Penelitian, 2019.

Berdasarkan Tabel 2 sayur bayam memiliki persentase peningkatan tertinggi karena frekuensi konsumen terhadap sayur bayam organik juga tinggi. Tingginya persentase peningkatan pada bayam sedangkan nilai rata-rata maksimum WTP tidak terlalu tinggi bisa karena pemahaman konsumen terhadap sayur organik semakin meningkat bahwa untuk mendapatkan manfaat dari sayur organik tidak harus dengan harga yang terlalu ekstrem hal ini dibuktikan dengan sayur bayam organik banyak diminati oleh konsumen. Alasan utama konsumen mengkonsumsi bayam organik karena harganya yang terjangkau, mudah ditemui dan kandungan gizi dari bayam dianggap lebih tinggi dari sayur lain. Bayam organik paling banyak dikonsumsi dari rentang usia muda sampai tua dibandingkan dengan jenis sayur lainnya. Artinya wawasan pengetahuan konsumen semakin meningkat terhadap kandungan gizi dari bayam organik yang sangat baik dan diperlukan untuk tubuh. 
Fajria, F., Ethika, D., Kusnaman, D. : Analisis Kesediaan Membayar ...
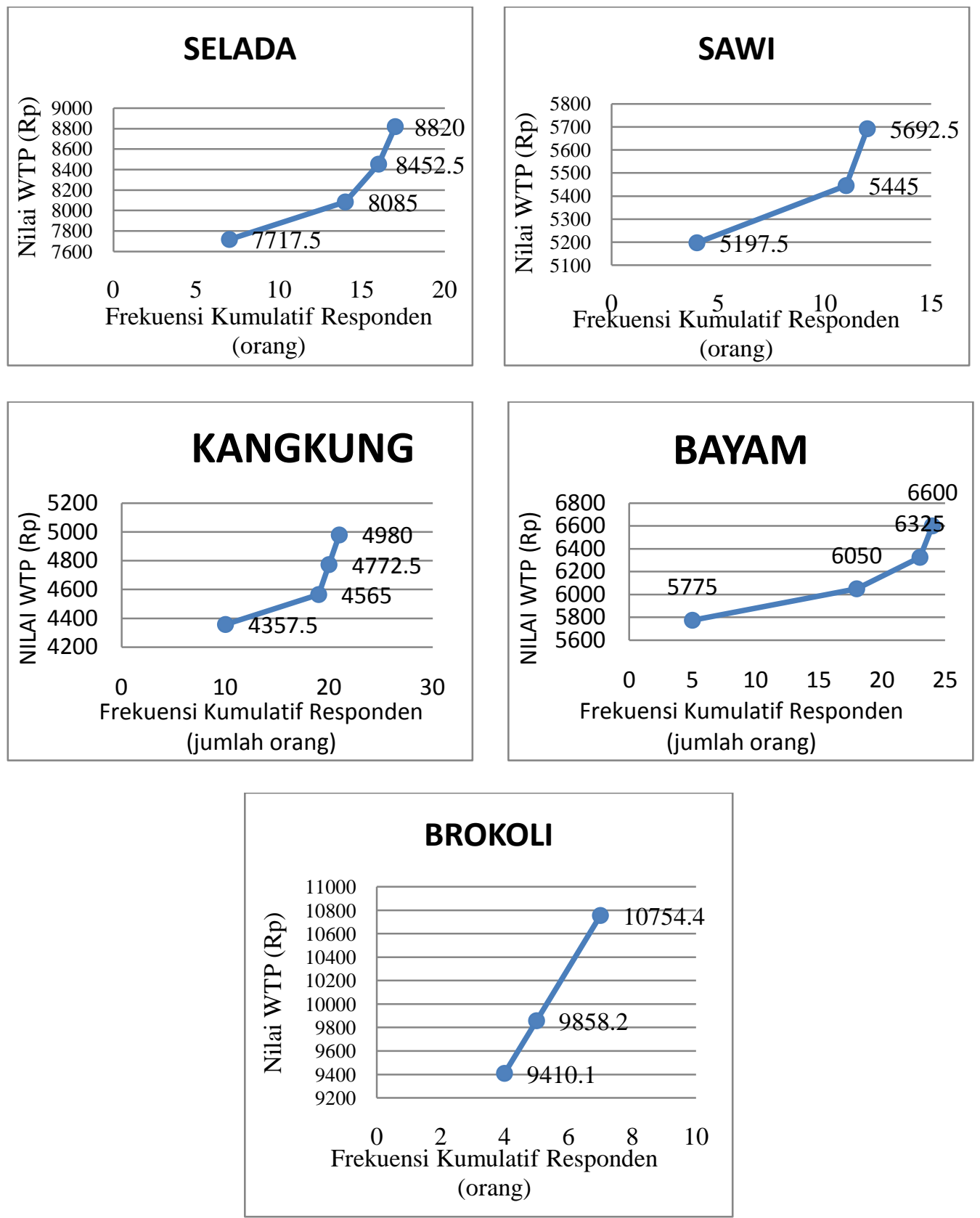

Gambar 1. Kurva WTP

2. Kurva WTP

Kurva WTP responden dibentuk menggunakan jumlah kumulatif dari jumlah individu yang memilih suatu nilai WTP. Hubungan kurva tersebut menggambarkan tingkat WTP yang bersedia dibayarkan dengan jumlah responden yang bersedia membayar pada tingkat WTP tersebut. Kurva WTP per jenis sayur disajikan pada Gambar 1.

Masing-masing kurva WTP menunjukkan pergerakan mengarah ke atas dan ke kanan. Hal tersebut menunjukkan bahwa terdapat responden yang bersedia membayar dengan harga yang semakin tinggi. Karena titik terendah merupakan nilai awal atau titik lelang dengan nilai terendah, maka pergerakan kurva ke atas menunjukkan nilai WTP yang semakin meningkat dan pergerakan kurva ke kanan menunjukkan bertambahnya jumlah responden yang bersedia membayar. Pergerakan kurva dari suatu titik ke titik selanjutnya menunjukkan pergerakan yang 
Fajria, F., Ethika, D., Kusnaman, D. : Analisis Kesediaan Membayar ...

berbeda-beda, terdapat kurva yang berbentuk curam dan landai. Hal tersebut bergantung dengan frekuensi responden yang memilih suatu nilai WTP. Semakin besar selisih jumlah responden pada suatu titik WTP ke titik selanjutnya, maka semakin landai bentuk kurvanya. Sebaliknya, semakin sedikit selisih jumlah responden pada suatu titik WTP ke titik selanjutnya, maka semakin curam bentuk kurvanya.

\section{Agregasi WTP}

Agregasi dari total WTP tiap komoditas adalah nilai keseluruhan dari nilai yang bersedia dibayarkan oleh seluruh responden dalam penelitian. Nilai agregasi WTP diperoleh dari perkalian rata-rata antara nilai rata-rata WTP tiap komoditas dengan populasi responden pada nilai WTP tersebut. Nilai agregasi WTP perlu diketahui agar pemasar mendapatkan informasi mengenai nilai penjualan dengan nilai maksimum yang bersedia dibayarkan konsumen dari penjualan masing-masing jenis sayur. Hasil perhitungan agregasi WTP dapat dilihat pada Tabel 3.

Tabel 3. Agregasi WTP

\begin{tabular}{cc}
\hline Jenis Sayur & Agregasi WTP $(\mathrm{Rp})$ \\
\hline Selada & 136382,93 \\
Sawi & 64567,8 \\
Kangkung & 94427,025 \\
Bayam & 145860 \\
Brokoli & 69038,767 \\
\hline
\end{tabular}

Sumber: Data Primer, 2019.

Berdasarkan Tabel 3, bayam organik memiliki nilai agregasi yang tinggi artinya kesediaan membayar terhadap sayur bayam tinggi. Hasil penelitian di lapangan menunjukkan banyak konsumen yang memiliki ketertarikan pada sayur bayam organik khususnya bayam merah organik karena ketersediaan membayar bayam merah organik sangat tinggi disebabkan harga bayam merah organik cukup terjangkau dan banyak disukai dari rentang usia muda sampai tua.
Faktor-Faktor yang Memengaruhi Kesediaan Membayar

Analisis regresi logistik digunakan untuk mengetahui faktor-faktor yang mempengaruhi kesediaan membayar sayuran organik. Variabel independen yang diduga mempengaruhi kesediaan membayar konsumen produk sayur organik adalah usia, jenis kelamin, tingkat pendidikan, status pernikahan, pekerjaan, pendapatan perbulan, harga produk dan penilaian konsumen terhadap kualitas produk. Berikut hasil perhitungan analisis regresi logistik menggunakan program SPSS 20 dapat dilihat pada Tabel 4.

Tabel 4. Hasil pengolahan regresi logistik

\begin{tabular}{|c|c|c|}
\hline \multicolumn{3}{|c|}{ Omnibus Test of Model Coefficients (Model) } \\
\hline Chi-square & Df & Sig. \\
\hline 25,575 & 8 & 0,001 \\
\hline \multicolumn{3}{|c|}{ Model Summary } \\
\hline $\begin{array}{c}2 \text { Log } \\
\text { likehood }\end{array}$ & $\begin{array}{c}\text { Cox \& Snell R } \\
\text { square }\end{array}$ & $\begin{array}{c}\text { Nagelkerke R } \\
\text { square }\end{array}$ \\
\hline 64,849 & 0,23 & 0,381 \\
\hline \multicolumn{3}{|c|}{ Hosmer and Lemeshow Test } \\
\hline Chi-square & Df & Sig. \\
\hline 3,198 & 8 & 0,921 \\
\hline
\end{tabular}

Overall Precentage (\%) 82,7

Sumber: Data Primer, 2019.

Responden yang digunakan dalam analisis regresi logistik adalah 98 orang karena terdapat dua data outlier atau data pengganggu yang ekstrem. Hasil uji $G$ atau uji secara serempak terdapat pada tabel Omnibus Test of Model Coefficients menunjukkan signifikansi hitung sebesar $0.001<0,05$, artinya $\mathrm{H} 0$ ditolak atau variabel independen secara serempak memiliki pengaruh secara nyata terhadap variabel dependen atau WTP. Hasil output pada Model Summary melihat kemampuan variabel independen dalam menjelaskan dependen. Nilai Nagelkerke $R$ Square sebesar 0,381 menunjukkan bahwa kemampuan variabel independen dalam menjelaskan variabel dependen sebesar $38,1 \%$ dan terdapat $61,9 \%$ faktor lain yang menjelaskan variabel dependen diluar penelitian ini. Hosmer and Lemeshow Test adalah uji untuk menentukan ketepatan model yang telah dibentuk. Nilai sig Hosmer and Lemeshow Test $(0,921>0.05)$, artinya $\mathrm{H} 0$ 
diterima yakni model regresi logistik mampu menjelaskan data dan tidak terdapat perbedaan antara model dan nilai observasinya. Hal ini menunjukkan bahwa persamaan regresi logistik dapat digunakan untuk menjelaskan hubungan variabel independen dan variabel dependen. Berdasarkan hasil output Classification Table dapat ditunjukkan bahwa model regresi logistik yang digunakan telah baik karena ketepatan model penelitian ini dengan benar sebesar $82,7 \%$ dari kondisi yang terjadi sehingga model ini layak. Sedangkan untuk uji secara parsial dengan uji Wald dapat dilihat pada Tabel 5.

Berdasarkan hasil uji Wald pada Tabel 5, variabel independen yang memiliki nilai $p$ value $<\alpha(0,05)$ mempengaruhi variabel dependen atau kesediaan membayar secara parsial. Diketahui bahwa usia, jenis kelamin, status pernikahan, harga dan kualitas tidak berpengaruh terhadap kesediaan membayar sayuran organik, sedangkan faktor-faktor yang mempengaruhi kesediaan membayar adalah tingkat pendidikan, pekerjaan, dan pendapatan.

Faktor pendidikan berpengaruh positif terhadap keputusan pembelian sayur organik. Berdasarkan hasil penelitian menunjukkan bahwa responden terbanyak yang memutuskan untuk membeli sayuran organik adalah responden yang menempuh pendidikan setingkat Strata 1. Terdapat pengaruh secara nyata tingkat pendidikan terhadap kesediaan membayar sayuran organik, karena tingkat pendidikan secara langsung maupun tidak langsung mempengaruhi pola pikir seseorang, yang kemudian akan mempengaruhi dalam kesediaan membayar lebih. Responden yang memiliki tingkat pendidikan lebih tinggi, mempunyai ilmu pengetahuan dan wawasan yang luas, serta memiliki pemahaman yang lebih baik dalam menerima informasi mengenai sayuran organik. Mereka lebih berorientasi pada cara hidup yang lebih sehat dengan cara mengkonsumsi sayuran organik.

Faktor pekerjaan signifikan terhadap kesediaan untuk membayar lebih sayuran organik $(0,018<0,05)$ dan berpengaruh positif terhadap kesediaan membayar sayur organik artinya konsumen yang memiliki pekerjaan akan mengambil keputusan untuk bersedia membayar lebih terhadap produk sayuran organik. Berdasarkan data dilapangan menujukkan bahwa rata-rata konsumen sayur organik bekerja sebagai pegawai swasta, karena pekerjaan seseorang akan menentukan pola kosumsi individu dan keluarga karena terkait dengan pendapatan yang dialokasikan untuk kegiatan konsumsi individu dan keluarganya.

Hal ini diperkuat oleh penelitian Dipeolu et al. (2016) yang menyatakan bahwa pengalaman kerja positif mempengaruhi pembayaran sayur organik, karena peningkatan pendapatan pada usia pekerjaan yang panjang.

Faktor pendapatan signifikan terhadap kesediaan membayar sayuran organik $(0,036<$ $0,05)$ dan memiliki pengaruh negatif $(-1,190)$ yang artinya bahwa apabila terjadi kenaikan kesediaan membayar maka akan menurunkan tingkat pendapatan. Berdasarkan penelitian dilapang, beberapa konsumen yang memiliki Faktor pendapatan signifikan terhadap kesediaan membayar sayuran organik $(0,036<$ $0,05)$ dan memiliki pengaruh negatif $(-1,190)$ yang artinya bahwa apabila terjadi kenaikan kesediaan membayar maka akan menurunkan tingkat pendapatan.

Berdasarkan penelitian, beberapa konsumen yang memiliki jumlah pendapatan keluarga yang lebih tinggi akan mampu

Tabel 5. Uji Wald

\begin{tabular}{lccccc}
\hline \multicolumn{1}{c}{ Variabel } & $\begin{array}{c}\text { Koefisien } \\
(\mathrm{B})\end{array}$ & Wald & P-value (sig.) & $\begin{array}{c}\text { Odds Ratio } \\
(\operatorname{Exp}(\mathrm{B}))\end{array}$ & Kesimpulan \\
\hline Usia & 0,029 & 0,520 & 0,471 & 1,029 & Tidak berpengaruh \\
Jenis Kelamin & $-21,626$ & 0,000 & 0,998 & 0,000 & Tidak berpengaruh \\
Pendidikan & 1,569 & 8,404 & 0,004 & 4,800 & Berpengaruh \\
Status Pernikahan & 0,210 & 0,037 & 0,848 & 1,234 & Tidak berpengaruh \\
Pekerjaan & 0,765 & 5,581 & 0,018 & 2,149 & Berpengaruh \\
Pendapatan & $-1,190$ & 4,389 & 0,036 & 0,304 & Berpengaruh \\
Harga & $-0,221$ & 0,511 & 0,475 & 0,801 & Tidak berpengaruh \\
Kualitas & 0,223 & 0,291 & 0,590 & 1,250 & Tidak berpengaruh \\
\hline Sum
\end{tabular}

Sumber: Data Primer, 2019. 
untuk memenuhi kebutuhan yang lebih baik, yaitu dalam hal ini adalah membeli sayuran organik sebagai salah satu bahan pangan yang bermutu baik. Hal ini sesuai dengan pendapat Fazrina et al. (2013) yang mengemukakan bahwa pendapatan yang tinggi memungkinkan konsumen untuk melaksanakan kegiatan atau kebutuhan lainnya yang lebih baik karena cukupnya dana yang mereka miliki.

Berdasarkan nilai odds ratio yang dapat dilihat dari nilai $\exp (\mathrm{B})$ dari hasil uji wald menujukkan bahwa nilai Exp (B) pada variabel tingkat pendidikan sebesar 4,800 menjelaskan bahwa konsumen dengan tingkat pendidikan lebih tinggi memiliki peluang 4,800 kali lebih besar untuk bersedia membayar dibandingkan konsumen dengan tingkat pendidikan lebih rendah. Konsumen yang memiliki pendidikan lebih tinggi dianggap bisa dengan lebih mudah untuk menerima informasi yang ada termasuk tentang pentingnya mengkonsumsi sayuran organik.

Nilai Exp (B) variabel pekerjaan sebesar 2,149 menjelaskan bahwa konsumen yang bekerja memiliki peluang 2,149 kali lebih besar untuk bersedia membayar dibandingkan konsumen yang tidak bekerja. Berdasarkan hasil wawancara peneliti di lapangan, beberapa dari konsumen pekerja swasta tidak memiliki banyak waktu untuk berbelanja dipagi hari sehingga memutuskan berbelanja setelah pulang bekerja di supermarket terdekat, ada pula beberapa yang bekerja dibidang kesehatan. Hal ini juga bisa disebabkan oleh lingkungan sekitar pekerjaan sehingga mengkonsumsi sayuran organik.

Nilai Exp (B) sebesar 0,304 mengartikan bahwa konsumen dengan pendapatan per bulan lebih tinggi memiliki peluang 0,304 kali lebih besar untuk bersedia membayar dibandingkan dengan konsumen dengan jumlah pendapatan yang lebih kecil. Berdasarkan wawancara pada saat turun lapang, beberapa konsumen yang memiliki pendapatan cukup tinggi akan lebih loyal untuk pembelian sayur organik yang lebih mahal.

\section{KESIMPULAN DAN SARAN}

Berdasarkan hasil dan pembahasan analisis kesediaan membayar terhadap sayuran organik di pasar modern Purwokerto dapat disimpulkan bahwa karakteristik konsumen dan hubungannya dengan bersedia atau tidaknya membayar akan produk sayuran organik di pasar modern Purwokerto mayoritas konsumen perempuan dengan rata-rata usia antara 27 tahun, kemudian status di dominasi oleh konsumen yang sudah menikah, dengan tingkat pendidikan tertinggi adalah Strata 1, dan pekerjaan yang mendominasi adalah pegawai swasta, serta rata-rata respoden yang memiliki pendapatan sebesar $\mathrm{Rp} 4.500 .000$ memiliki jumlah kesediaan membayar terbesar. Nilai rata-rata maksimum WTP konsumen produk sayur organik tertinggi yaitu pada komoditas sayur bayam dan yang terendah adalah sayur kangkung. Faktor yang memengaruhi kesediaan membayar secara signifikan pada selang kepercayaan $95 \%$ adalah pendidikan, pekerjaan, dan pendapatan. Saran yang dapat diberikan sebagai tindak lanjut dari hasil penelitian yaitu perlu adanya peningkatan kepedulian dan kesadaran untuk memahami manfaat dari sayuran organik agar bisa dikonsumsi oleh semua masyarakat baik dari yang berpendidikan dan berpendapatan rendah sampai tertinggi. Petani diharapkan menerapkan sistem pertanian organik tanpa melibatkan bahan-bahan kimia dalam proses budidaya.

\section{DAFTAR PUSTAKA}

Dipeolu, A., Akerele, dan Oyawole. 2016. Factors Influencing Willingness To Pay For Organic Vegetables Among Civil Servants In A Developing Country. International Journal of Vegetable Science, 22(2), 121-128.

Kusumaningsih, D., Irianto, H., dan Antriyandarti, E. 2019. Effects of health consciousness and environmental attitude on intention towards organic food purchase. IOP Conf. Series: Materials Science and Engineering 633 (2019) 012052.https://doi.org/10.1088/17 57-899X/633/1/012052.

Lemeshow, S., dan Levy, P.S. 1997. Sampling of Populations Methods and Application. New York: Wiley Publisher.

Priambodo, L. H., dan Najib, M. 2014. Analisis Kesediaan Membayar (Willingness to 
Fajria, F., Ethika, D., Kusnaman, D. : Analisis Kesediaan Membayar ...

Pay) Sayuran Organik dan Faktor-Faktor yang Mempengaruhinya. Jurnal Manajemen Dan Organisasi, 5(1), 1-14.

Maddala, G. S. 2006. Introduction to Econometrics. 3rd Edition. Hoboken, New Jersey: John Wiley \& Sons Pulishers.

Mayrowani. 2012. Pengembangan Pertanian Organik di Indonesia. Forum Penelitian Agro Ekonomi, 30(2), 91-108.

Fazrina, R., Marsaulina, I., dan Naria, E. 2013. Hubungan Karakteristik dan Pengetahuan Tentang Lingkungan Sehat dengan Keputusan Konsumen Dalam Membeli Sayuran Organik di Carrefour
Plaza Medan Fair. Jurnal Lingkungan Dan Keselamatan Kerja, 2(3), 1-9.

Suharjo, B. 2008. Analisis Regresi Terapan dengan SPSS. Yogyakarta: Graha Ilmu.

Wooldridge, J. M. 2013. Introductory Econometrics : A Modern Approach. 5th ed. $\mathrm{OH}$ : South-Western Cengage Learning.

Yakin. 1997. Ekonomi Sumber Daya dan Lingkungan; Teori dan Kebijaksanaan Pembangunan Berkelanjutan. Jakarta: Akademika Presindo. 